\title{
Tumor Microenvironment in Head and Neck Squamous Cell Carcinomas
}

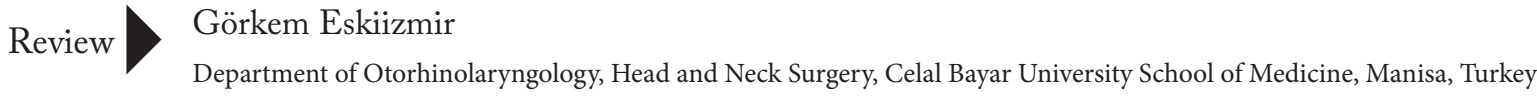

Abstract Recent studies about solid tumors demonstrated that tumor microenvironment has an important role in tumor progression, aggressivity, and metastasis process, in addition to genetic aberrations and molecular alterations of cancer cells. Therefore, the crosstalks between cancerous and noncancerous cells and metabolic changes in tumor microenvironment cause significant detrimental effects. The purpose of this review is to present the role and effect of noncancerous cells and their crosstalks with cancer cells, metabolic changes in tumor microenvironment, and to discuss the clinical significance of all these factors with respect to the current literature.

Keywords: Carcinoma, squamous cell of head and neck, head and neck neoplasms, tumor microenvironment

"People should know the strategy: those who learn the strategy live and those who do not are doomed to perish!"

Sun Tzu, The Art of War.

\section{Introduction}

Head and neck cancers define epithelial malignancies of the oral cavity, pharynx, larynx, paranasal sinuses, and nasal cavity. Head and neck cancers comprise $6 \%$ of all cancers and are in sixth place in order of frequency among all cancers. It is estimated that approximately 650,000 new cases develop worldwide each year and that cancer-related death occurs in approximately 350,000 cases (1). The most common histopathological type in head and neck cancers is squamous cell carcinoma, and besides genetic alterations, its known major risk factors among environmental factors are tobacco/ cigarette consumption, alcohol consumption, and exposure to chemical and viral agents (2). In studies, particularly those conducted in recent years, the relationship between oral cavity and oropharynx squamous cell carcinomas and the human papilloma virus (human papilloma virus 16 and 18) has been clearly demonstrated (3).

It is known that the inactivation of tumor suppressor genes and/or the many genetic mutations and epigenetic changes with the activation of proto-oncogenes play a role in the development of head and neck squamous cell carcinomas. Telomerase reactivation has been revealed in approximately $90 \%$ of premalignant lesions developing in this region; this enzyme plays an important role in the continuity of telomeres and in the cell gaining immortality, specifically in deoxyribonucleic acid (DNA) (After a normal cell divides a maximum of 50-80 times, according to the Hayflick limit, it sustains apoptosis. However, cancer cells do not have this limit; therefore, they are defined as "im- mortal.") (4). The loss of $9 \mathrm{p} 21$ is among the most common (70-80\%) genetic change in head and neck squamous cell carcinomas (5). Along with these, the inactivation of $\mathrm{p} 16$ and loss of $3 \mathrm{p}$ due to deletions, point mutations, or promoter hypermethylation play an important role in carcinogenesis (6). In $50 \%$ of head and neck cancers, a loss in $17 \mathrm{p}$ heterozygosity and TP53 point mutations can also be seen (7). In addition, the overexpression of Cyclin D1 was found to be closely associated with aggressive tumor characteristics (8).

In cancer, there are significant steps that cancer cells should surpass in the process, starting from carcinogenesis and continuing to distant metastases (Figure 1). They are as follows:

(i) Local tumor proliferation and infiltration,

(ii) Tumor cells' reaching the lymphatic/circulatory system (intravasation),

(iii) Tumor cells' getting out of the circulation in the metastatic distant organ and reaching the tissue (extravasation), and

(iv) Proliferation and progression in the organ with developing metastasis.

To successfully complete the above-mentioned challenging process, cancer cells need to gain some special abilities (9):

1. To show resistance to cell death (apoptosis),

2. To multiply many times while having immortality,

3. To hide from the devastating/destroying effects of the immune system,

4 To use cells in the immune system in their own favor, 


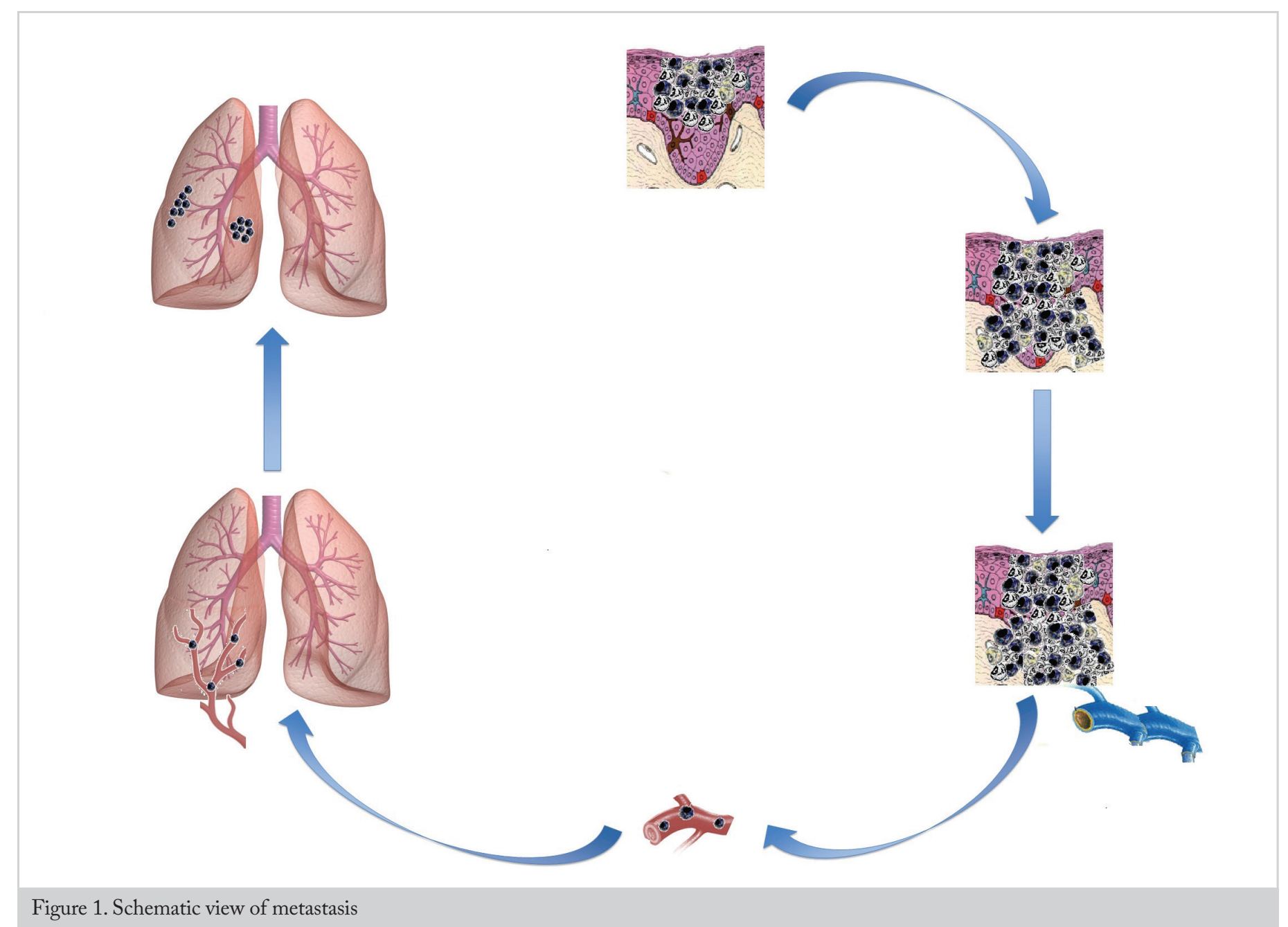

5. To lose their sensitivity against growth suppressive cytokine/metabolites,

6. To be able to make changes in the intracellular energy system and metabolism,

7. To cause unstable genome mutation,

8. To gain the ability of epithelial-mesenchymal transition,

9. To gain the ability to invade tissues and to use surrounding cells (inflammatory cells, fibroblasts, etc.) in their favor in order to achieve this,

10. To increase the tumor-provoking inflammation,

11. To trigger/increase lymphangiogenesis and/or angiogenesis,

12. To make hematogenic and/or lymphatic metastasis,

13. To gain the ability of mesenchymal-epithelial transition, and

14. To be colonized by multiplying in remote organs.

The impact of the communication between cancer cells and cells located in the tumor microenvironment in cancer progression was emphasized in The 5th International Conference on Tumor Microenvironment: Progression, Therapy, and Prevention, 2009 (10). In the article where basic formation mechanisms of cancer were presented, Hanahan and Weinberg (11) indicated the role of the microenvironment in the development of abilities/attitudes or in the increase of their impact that cancer cells need for carcinogenesis, tumor growth, or metastasis.

The main objective of this review is to present the role and importance of the tumor microenvironment in carcinogenesis and cancer cell biology, tumor progression, metastasis process, treatment resistance, and prognosis in head and neck squamous cell carcinomas within the framework of current research and evidence.

\section{An overview of the tumor microenvironment}

The tumor microenvironment is an interactive, organized, and dynamic environment where cancer cells as well as many different cellular and biochemical structures exist together and are continuously in contact and interact with each another (12). The main structures in this area are the parenchyma, stroma, growth factors, lymphokines and cytokines, and inflammatory and matrix metalloproteinase enzymes (Figure 2). While cancer cells and cancer stem cells are located in the parenchyma, nonmalignant cells (inflammatory cells, cancer-associated fibroblasts, angiogenic vascular cells, and sometimes adipocytes) and extracellular matrix constitute the stroma. Inflammatory cells play an important role in providing mitogenic growth factors for 


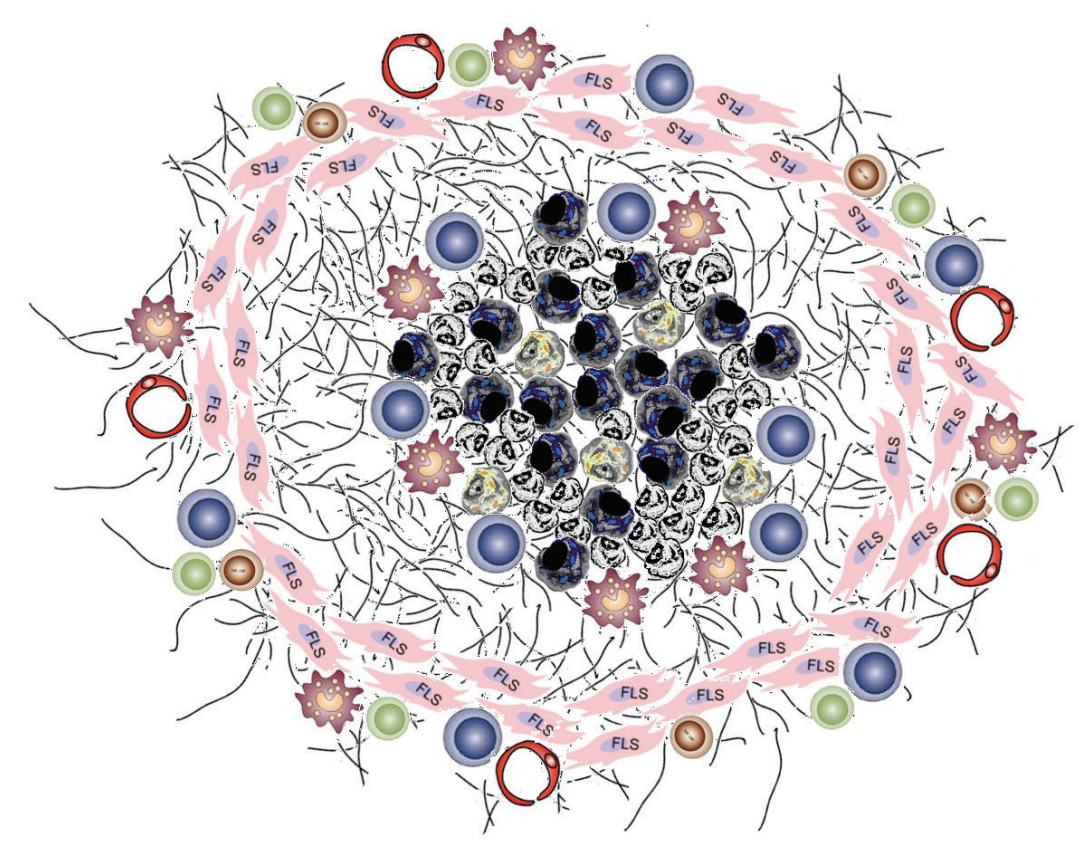

Extracellular matrix proteins
Cancer cell
Cancer stem cell
Fypoxic / apoptotic cancer cell
(-) T-cells
Natural killer cells
B-cell
(1) Pericyte

Figure 2. A schematic view of the tumor microenvironment

cancer cells, triggering angiogenesis and in cancer cells' showing resistance to cell death, escaping from the immune system, and gaining the ability of invasion/metastasis (13). Cancer-associated fibroblasts are also effective in reorganizing the cellular metabolism. The extracellular matrix is a dynamic structure with the role of a 3-dimensional pattern where all cells exist, and it contains many different proteins, glycoproteins, proteoglycans, and polysaccharides with different biochemical properties within the structure; mainly, these are collagen, fibrin, fibronectin, proteoglycans, and hyaluronan (14).

\section{The effect of inflammatory cells around the microenvironment of head and neck squamous cell carcinoma tumors}

The first hypothesis about the relationship between cancer development and inflammation was put forward by Virchow (15). Cancer cells safeguard their life and growth with chronic inflammation that they create in the microenvironment of the cancer cells. Though it is considered that inflammation creates a beneficial effect in the removal of pathological structures and in the destruction of cancer cells, inflammatory response that is unorganized and managed by the cancer cells creates an opportunity for the development of the tumor and for the cancer cells to evade the devastating effects of the immune system. Research conducted in head and neck cancers have clearly revealed that local, regional, and systemic inflammatory responses are dysfunctional $(16,17)$.

The major inflammatory cells that play a role in the tumor microenvironment are $\mathrm{T}$ lymphocytes, natural killer cells, and tumor-associated macrophages. The distribution of these cells in the solid tumor microenvironment shows heterogeneity, while granulocytes, mast cells, and macrophages are located around tumors, and natural killer cells are located in the stroma and $\mathrm{T}$ lymphocytes are located in the microenvironment margins and lymph nodes (18). T lymphocytes are divided into two groups: cytotoxic CD8+ T lymphocytes and CD4+ T lymphocytes. CD4+ T lymphocytes are divided into two groups: $T$ helper cells exhibiting different behaviors and characteristics and $\mathrm{T}$ regulatory cells. Cytotoxic CD8+ T lymphocytes play a major role in the antitumoral response and an active role in the destruction of tumor cells being recognized, and therefore their presence in the tumor microenvironment often indicates a favorable prognosis (19). In addition, $T$ helper cells play a role in helping CD8+ T lymphocytes and in enhancing the antitumor effect. However, $T$ regulatory cells are also effective in tumor progression because of their immunosuppressive effects and because they inhibit the functions of cytotoxic CD8+ T lymphocytes. As in many patients with solid tumors, functional disorders in circulating and tumor-infiltrating $\mathrm{T}$ lymphocytes have also been seen in patients with head and neck cancers $(18,20)$. Also, when blood samples taken from healthy individuals and patients with head and neck cancer were compared, the number of $\mathrm{T}$ regulatory cells was found to be higher by a significant ratio $(21,22)$. In a study in which they examined the number of $\mathrm{T}$ regulatory cells in tongue cancer, Hanakaw et al. (23) concluded that a high number of $\mathrm{T}$ regulatory cells are poor prognostic factors.

A high proportion of cytotoxic $\mathrm{CD} 8+\mathrm{T}$ lymphocytes/T regulatory cells was reported to be a good prognostic factor in many solid tumor microenvironments, such as hepatocellular, breast, 
and lung cancer (24). In the study they conducted in the tumor specimens of 87 oral cavity cancer patients, Watanabe et al. (25) found low stromalsitotoksik CD8+ T-lymphocyte counts and a high number of stromal $\mathrm{T}$ regulatory cells to be associated with low survival, but they determined that the total number of $\mathrm{T}$ regulatory cells did not have an impact. Besides, it was revealed that the worst prognosis was in the group where the ratio of "cytotoxic CD8+ T lymphocyte/Regulatory" cells was low, and it was emphasized that this proportion alone was an independent prognostic factor. However, studies conducted in oropharynx cancer revealed different results from the other head and neck cancers. Although it was determined that high value of cytotoxic $\mathrm{CD} 8+\mathrm{T}$ lymphocytes is a positive prognostic factor in oropharyngeal cancer, the effect of the high value of $\mathrm{T}$ regulatory cells is controversial (26).

Tumor-associated macrophages (TAMs) play an important role in the extracellular matrix destruction and in restructuring of the tumor microenvironment, tumor cell motility, and triggering the angiogenesis. These cells are divided into two: proinflammatory (M1) and suppressive (M2) TAM. M1 TAMs demonstrate an antitumor effect thanks to the proinflammatory cytokines (IL$12,-23$, interferon, etc.) they produce. However, M2 TAMs suppress the antitumoral effect of M1 TAMs, trigger angiogenesis, and lead to tumor progression with the suppressive cytokines (IL-10, tumor growth factor-beta, etc.) that they produce. Tumor-associated macrophages cluster particularly in solid tumors with a hypoxic and necrotic environment and, therefore, they are often detected in head and neck cancers. In a meta-analysis on this subject, considerable evidence was presented on the grounds that a high level of TAM in head and neck cancers causes the overall survival to be low (27).

Natural killer cells are involved in the detection and destruction of cancer cells. However, even if they are settled in the stromal tumor microenvironment, they are rarely in contact with cancer cells. They indicate good prognosis in many solid tumors, such as colorectal, lung, renal, and gastric cancer (12). However, it was demonstrated that a significant reduction in the number of natural killer cells occurred in the cases of head and neck cancer (28).

\section{The effect of cancer-associated fibroblasts in the tumor microenvironment of head and neck squamous cell carcinoma}

Normal fibroblasts in a healthy person play an important role in the formation of the architecture of the tissue that they are in by producing the important components (type IV collagen, laminin, cytokines, etc.) of the extracellular matrix. They are commonly located in the stroma along the respiratory system. Fibroblasts activated with the paracrine signaling that occurs with tissue damage change into the myofibroblasts and, thus, play a role in wound contraction and in regulating the fibrous and inflammatory response. They express $\alpha$-smooth muscle actin and produce extracellular matrix components for the realization of these processes. In addition, fibroblasts proliferating for tissue repair in a cellular way sustain apoptosis with the completion of wound healing.
Cancer is characteristically defined as a "non-healing wound," and this process continues especially via cancer-associated fibroblasts (CAFs). CAFs located in tumor stromal microenvironment play a critical role; they are particularly effective in carcinogenesis, tumor progression, and metastasis $(29,30)$. In the CAF activity study, which they conducted with the samples taken from the head and neck cancer tumor stroma, Rosenthal et al. (31) revealed that CAFs play an important role in the production of many protease enzymes (membrane type 1-matrix metalloproteinase (MMP), MMP1, MMP2, MMP3, MMP9, urokinase, etc.) that help the tumor gain an invasive character and that are effective in remodeling of the extracellular matrix. Cancer-associated fibroblasts may be formed as a result of genetic changes that occur in normal fibroblasts, and in the exposure of epithelial cells to epithelial-mesenchymal transition and endothelial cells to endothelial-mesenchymal change, or may directly arise from mesenchymal stem cells (32). Undergoing myofibroblastic changes, these cells have a phenotype characterized by dense ultrastructural $\alpha$-smooth muscle actin deposition. In addition, integrin $\alpha 6$ overexpression, which is important in cell adhesion and surface signaling, is also determined (17).

Cancer-associated fibroblasts constitute $50-70 \%$ of the volume of many solid epithelial tumors, such as pancreas, stomach, and breast cancers (33). CAFs play an important role in the development of the desmoplastic response, which is a characteristic of head and neck cancers (dense collagen deposition and the stromal desmoplasia). Kawashir et al. (34) demonstrated that desmoplasia was apparent in aggressive tumors and the myofibroblasts proliferation in tumor stroma was helpful in tumor invasion and metastasis in a clinicopathological study on oral cavity cancers. In addition, they reported that the survival rate due to disease in the group of $\alpha$-smooth muscle actin positive was statistically lower.

\section{Hypoxia in the tumor microenvironment}

Multiple metabolic changes develop depending on the interaction between cancer cells in the parenchyma and the stromal cells in the tumor microenvironment (Table 1). Hypoxia is the most important among these changes (35). Hypoxia ( $\mathrm{pO} 2<10$ $15 \mathrm{mmHg}$ ) describes the deficiency in oxygen levels occurring due to the imbalance between the oxygen levels that are needed and that are provided for this tissue. This imbalance in oxygen levels may fundamentally occur from vascular or pulmonary diseases, of which there are three types (35-37):

(i) Chronic hypoxia (diffusion-limited hypoxia): Low oxygen pressure (about 2-3\%) due to long-term low oxygen diffusion. Although normal, healthy cells cannot show resistance to chronic hypoxia, cancer cells may continue to live in this environment with metabolic changes and the adaptation abilities they have.

(ii) Acute hypoxia (perfusion-limited hypoxia): Reduction of oxygen pressure due to a sudden developing temporary/permanent reduction of the blood flow.

(iii) Hypoxia with reperfusion: Development of reoxygenation along with the provision of the flow after acute 
hypoxia. However, even if a physiological oxygen lev$\mathrm{el}$ is provided in this case, "reoxygenation injury" often develops due to the occurrence of free radical oxygen species. Free oxygen radicals occurring along with the reperfusion that develops after hypoxia in the tumor microenvironment may lead to chromosomal break, gene amplifications, and uncontrolled DNA replications.

\section{Hypoxia in the head and neck squamous cell carcinoma tumor microenvironment: mechanisms, effects, diagnostic methods and clinical significance}

When compared with the healthy tissues around many solid tumor microenvironments, such as breast, brain, cervix, prostate, rectum, and head and neck cancers, a significant level of hypoxia has been demonstrated (38). Heterogeneously distributed hypoxic areas at different levels were found in the microenvironment of $50-60 \%$ of locally advanced tumors (35). The basic mechanisms that play a role in hypoxia developing in the microenvironment of solid tumors are as follows:

(ii) Diffusion-limited hypoxia developing because of the distance ( $>70$ microns) of cancer cells to micro-vessels.

(ii) Perfusion-limited hypoxia developing as a result of functional and structural disorders (amorphous and chaotic vasculature system) in tumor micro-vascularization.

(iii) The general condition of the patient, cancer-induced cachexia, and insufficiency in tissue oxygenation due to anemia occurring as a result of the treatment.

It was demonstrated that hypoxia in the tumor microenvironment causes genetic instability in cancer cells and a deterioration in gene expression, which play an important role in the tumor's developing an invasion capability and gaining an aggressive character, radio-/chemotherapy treatment resistance, and metastasis development; all of which are negative prognostic factors (39-41). Therefore, detection of the presence and level of hypoxia in the tumor microenvironment is becoming increasingly important. Unfortunately, a "gold standard" technique is currently not available to determine the level of hypoxia in the tumor microenvironment. Currently, the main techniques used are those presented below $(36,42,43)$ :

(i) Electrophysiological measurement techniques: This is performed directly and invasively in the tumor microenvironment with polarographic $\mathrm{pO} 2$ electrodes. The ability to make direct measurements in the tumor microenvironment through this technique is its most important advantage. However, the heterogeneity of hypoxia in the tumor microenvironment and the difficulty of access to some areas are significant limitations.

(ii) Exogenous hypoxia markers: This is an indirect and invasive technique. Hypoxic cells in the tumor microenvironment are marked by the intravenous administration of nitroaromatics markers (pimo-, miso-, eta-nidazol) that are selectively connected to hypoxic cells $24-48$ hours prior to the biopsy. (iii) Radiological examinations: Direct and noninvasive dynamic contrast-enhanced magnetic resonance imaging is done with blood and tissue oxygen level specific magnetic resonance imaging techniques. Experimental and clinical studies on especially dynamic contrast-enhanced magnetic resonance imaging are widely available among these techniques. Dynamic contrast-enhanced magnetic resonance imaging can display the blood flow in the tumor microenvironment, vascular volume, and the permeability of blood vessels with high resolution.

(iv) Nuclear medicine examinations: This is performed directly and noninvasively with positron emission tomography-based imaging methods, particularly together with radiotracers (18F-MISO, 18F-PHASE: $18 \mathrm{~F}-\mathrm{HX} 4,18 \mathrm{~F}-\mathrm{EF} 5$, etc.) specific to hypoxia. The most commonly used radiotracer for determining hypoxia is $18 \mathrm{~F}-$ miso. Although promising results related to hypoxia measurement have been achieved in studies conducted using these radiotracers, the number of cases in the study is limited, and because they are not commonly found, the radiotracers could not enter routine clinical use.

(v) Assessment of endogenous hypoxia associated markers: This is the indirect detection of hypoxia associated factors [hypoxia-inducible factor (HIF)-1, $-2,-3$, carbonic anhydrase-9 (CA-9), osteopontin (OPN), etc.] in tumor tissue. These biomarkers increase the correlations with the hypoxia in the tumor microenvironment. Thus, information may be obtained about the hypoxia level of the tumor by examining these biomarkers, and it is possible to then comment on the radio/chemotherapy resistance and prognosis. However, the most important limitation of these techniques is that different results can be obtained depending on the area of biopsy, due to heterogeneity of the tumor microenvironment. However, the potential increase in biomarkers due to causes other than hypoxia can also lead to detection failures of the hypoxia level.

Many signaling networks are activated with the development of hypoxia in the tumor microenvironment; mainly, these are HIFs, OPN, and CA-9. HIFs play the role of a "hypoxia sensor" in the tumor microenvironment. These proteins are transcriptional complexes and consist of two heterodimers: HIF- $\alpha$ and HIF- $\beta(44,45)$. Today, they are classified into three types of HIFs: HIF-1, -2 , and -3 . Among these, HIF-1 is the one on which most research and clinical trials have focused. Cells are continuously synthesizing HIF- $1 \alpha$ in normoxic environments, but they have a short duration of half-lives because they rapidly become hydroxylated depending on the reaction of oxygen with the aid of specific hydroxylase enzymes. The hydroxylated HIF-1 $\alpha$ protein becomes a substrate for the von Hippel-Lindau protein targeting this protein and is destroyed after the ubiquitination process. However, along with the reduction of the oxygen concentration in the environment (hypoxia/anoxia), HIF-1 $\alpha$ does not get hydroxylated and its concentration in the environ- 
Table 1. Metabolic changes developing in the microenvironment of solid tumors

Increase in chaotic and amorphous vascular embodiment

Increase in perfusion failure

Increase in perfusion heterogeneity

Increase in the permeability of tumor microvascularization

Increase in interstitial fluid pressure

Increase in lactate production

Decrease in food provision

Decrease in partial oxygen pressure

Decrease in the high energy structure production

Decrease in extracellular matrix $\mathrm{pH}$

ment increases because it is not destroyed. HIFs transcriptionally regulate the function of many genes and these genes play an important role in many stages of cancer development and progression, such as growth, development, apoptosis, epithelialmesenchymal transition, invasion ability, angiogenic signaling, and the regulation of energy metabolism (Table 2) (44-46). In the study where they researched the levels of HIF-1 and -2 in head and neck cancer cell lines and tumor tissues, Beasley et al. (47) suggested that a significant increase occurred in both biomarker expressions.

OPN is a multifunctional, negatively charged, acidic protein. Although expressed at high levels, particularly in the bone, it can also be synthesized by many different cells (macrophages, endothelial cells, and smooth muscle and epithelial cells) (48). OPN is inversely correlated with the expression of the von Hippel-Lindau protein that plays an important role in the destruction of HIF. Thus, the increase in the level of OPN in the tumor microenvironment reduces the expression of the von HippelLindau protein, and then, the destruction of HIF accordingly decreases. Le et al. (49) revealed the correlation between plasma OPN levels and tumor hypoxia in the study they conducted in the blood samples of patients with head and neck cancer.

CA-9 is a transmembrane glycoprotein that is a member of a large metalloenzyme family. The members of this family provide for the reversible transformation of $\mathrm{CO}_{2}$ to $\mathrm{HCO}_{3}$; thus, they play a role in fulfilling many important functions such as $\mathrm{pH}$ regulation of the extracellular matrix and microenvironment, respiration, and calcification. The increasing HIF level along with hypoxia in the tumor microenvironment also triggers the expression of CA-9. It has been reported that the level of CA-9 was high and closely associated with adverse survival in many solid tumors such as cervix, kidney, stomach, lung, and head and neck cancers (50). In a study conducted in head and neck cancer cell lines and tumor specimens, it was found that CA-9 was expressed at an increased rate and was higher in advanced stage tumors (51).

The first study in which the clinical effects of hypoxia in head and neck cancers was examined was conducted in 1996 by Nordsmark et al. (52), with measurements performed with Ep-
Table 2. Target genes where the hypoxia-inducible factor is effective in cancer development

\begin{tabular}{|c|c|}
\hline Function & Target gene \\
\hline Erythropoiesis/iron metabolism & $\begin{array}{l}\text { Erythropoietin } \\
\text { Transferrin } \\
\text { Transferrin receptor } \\
\text { Ceruloplasmin }\end{array}$ \\
\hline Angiogenesis & $\begin{array}{l}\text { Vascular endothelial growth factor } \\
\text { Endocrine gland derived vascular } \\
\text { endothelial growth factor } \\
\text { Leptin } \\
\text { Transforming growth factor } \beta\end{array}$ \\
\hline Vascular tone & $\begin{array}{l}\text { Nitric oxide synthase } \\
\text { Heme oxygenase } 1 \\
\text { Endothelin } 1 \\
\text { Adrenomedullin } \\
\alpha \text {-adrenergic receptor }\end{array}$ \\
\hline Matrix metabolism & $\begin{array}{l}\text { Matrix metalloproteinases } \\
\text { Plasminogen activator receptor and } \\
\text { inhibitor } \\
\text { Collagen prolyl hydroxylase }\end{array}$ \\
\hline Energy metabolism & $\begin{array}{l}\text { Adenylate kinase-3 } \\
\text { Aldolase-A,-C } \\
\text { Carbonic anhydrase-9 } \\
\text { Enolase-1 } \\
\text { Glucose transporter-1,-3 } \\
\text { Glyceraldehyde phosphate dehydrogenase } \\
\text { hexokinase } 1.2 \\
\text { Lactate dehydrogenase-A } \\
\text { Pyruvate kinase M } \\
\text { Phosphofructokinase L } \\
\text { Phosphoglycerate kinase } 1 \\
\text { 6-phospho fructo-2-kinase/fructose-2, } \\
\text { 6-bisphosphate-3 }\end{array}$ \\
\hline A cell proliferation/survival & $\begin{array}{l}\text { Insulin-like growth factor- } 2 \\
\text { Transforming growth factor- } \alpha \\
\text { Adrenomedullin }\end{array}$ \\
\hline Apoptosis & $\begin{array}{l}\text { Bcl-2* } \\
\text { Nip3-like protein } X^{* *}\end{array}$ \\
\hline
\end{tabular}

*B-cell lymphoma-2

**19 kD interacting protein-3

pendorf polarographic oxygen electrodes (KIMOC 6650; Sigma pO2 Histograph; Eppendorf, Hamburg, Germany) in the lymph nodes of 34 advanced stage head and neck cancer patients in whom radiotherapy was planned. Experts determined the level of hypoxia as pO2 of $2.5 \mathrm{mmHg}$ in this study and divided the patients into two groups: those below and those above this level. In the results from this study, while locoregional 
failure developed in $22 \%$ of patients with $\mathrm{PO} 2$ of $<2.5 \mathrm{mmHg}$, this rate was determined as $6 \%$ in patients with $\mathrm{pO} 2$ of $>2.5$ $\mathrm{mmHg}$. In addition, it was found that the $\mathrm{pO} 2$ level was an independent factor for the radiotherapy response. Brizel et al. (53) determined $\mathrm{pO} 2$ of $10 \mathrm{mmHg}$ as the level of the hypoxia border in a study where they made polarographic measurements in both the primary tumor area and the lymph nodes of 63 head and neck cancer patients in whom radiotherapy was planned. In this study, it was concluded that 2 years of locoregional control (pO2<10 mmHg: 30\%, pO2>10 mmHg: 73\%) in disease-free patients (pO2<10 mmHg: 26\%, pO2>10 mmHg: 73\%) and overall survival (pO2<10 mmHg, 35\%, pO2>10 mmHg: 83\%) were negative in hypoxic patients. In conclusion, it was speculated that hypoxic examinations before treatment are a good method for patient choice. Although different hypoxia limits were determined in other studies, the common result is that hypoxia has a negative prognostic effect (54).

Moreover, in a randomized, double-blind, placebo-controlled study that the Danish Head and Neck Study Group published in 2005, 320 head and neck cancer patients were divided into three groups (high, medium, and low) according to their plasma OPN levels (55). At the end of this study, a high plasma OPN level was reported to be closely related to radiotherapy failure.

\section{Conclusion}

The inflammatory and non-inflammatory intercellular communication and environmental changes in head and neck squamous cell carcinomas in the tumor microenvironment play an important role in the progression and aggressiveness of cancer and the development of gaining the ability of making lymphatic and hematogenic metastasis. Inflammatory response dysfunction was demonstrated in head and neck cancers and functional disorders in circulating and tumor-infiltrating $\mathrm{T}$ lymphocytes. In addition, a low rate of "CD8+ cytotoxic $\mathrm{T}$ lymphocyte/T regulatory" was found to be a poor prognostic factor in head and neck cancers, except for the case of oropharynx cancers. Because head and neck cancers characteristically have a hypoxic environment, TAM clusters are often found in the tumor microenvironment. A high level of TAM leads to a low general survival. However, CAFs play an important role in the development of desmoplasia, which is a poor prognostic factor in head and neck cancers. Owing to these features, clarification of the changes of head and neck squamous cell carcinomas in the tumor microenvironment and development of targeted therapies are promising future treatment options.

Peer-review: Externally peer-reviewed.

Conflict of Interest: No conflict of interest was declared by the author.

Financial Disclosure: The author declared that this study has received no financial support.

\section{References}

1. Parkin DM, Bray F, Ferlay J, Pisani P. Global cancer statistics, 2002. CA Cancer J Clin 2005; 55: 74-108. [CrossRef]

2. Argiris A, Eng C. Epidemiology, staging, and screening of head and neck cancer. Cancer Treat Res 2003; 114: 15-60. [CrossRef]
3. D'Souza G, Kreimer AR, Viscidi R, Pawlita M, Fakhry C, Koch WM, et al. Case-control study of human papillomavirus and oropharyngeal cancer. N Engl J Med 2007; 356: 1944-56. [CrossRef]

4. McCaul JA, Gordon KE, Clark LJ, Parkinson EK. Telomerase inhibition and the future management of head-and-neck cancer. Lancet Oncol 2002; 3: 280-8. [CrossRef]

5. Mao L, Lee JS, Fan YH, Ro JY, Batsakis JG, Lippman S, et al. Frequent microsatellite alterations at chromosomes 9p21 and 3p14 in oral premalignant lesions and their value in cancer risk assessment. Nat Med 1996; 2: 682-5. [CrossRef]

6. Argiris A, Karamouzis MV, Ferris RL. Head and neck cancer. Lancet 2008; 371: 1695-709. [CrossRef]

7. Balz V, Scheckenbach K, Götte K, Bockmühl U, Petersen I, Bier $H$. Is the $\mathrm{p} 53$ inactivation frequency in squamous cell carcinomas of the head and neck underestimated? Analysis of p53 exons 2-11 and human papillomavirus 16/18 E6 transcripts in 123 unselected tumor specimens. Cancer Res 2003; 63: 1188-91.

8. Capaccio P, Pruneri G, Carboni N, Pagliari AV, Quatela M, Cesana BM, et al. Cyclin D1 expression is predictive of occult metastases in head and neck cancer patients with clinically negative cervical lymph nodes. Head Neck 2000; 22: 234-40.

9. Hanahan D, Weinberg RA. The hallmarks of cancer. Cell 2000; 100: 57-70. [CrossRef]

10. Mohla S, Witz IP. The 5th International Conference on Tumor Microenvironment: Progression, Therapy and Prevention Versailles, France, October 20-24,2009. Cancer Microenvironment 2010; 3: 1-5. [CrossRef]

11. Hanahan D, Weinberg RA: Hallmarks of cancer: The next generation. Cell 2011; 144: 646-74. [CrossRef]

12. Balkwill FR, Capasso M, Hagemann T. The tumor microenvironment at a glance. J Cell Sci 2012; 125: 5591-6. [CrossRef]

13. Hanahan D, Coussens LM. Accessories to the crime: Functions of cells recruited to the tumor microenvironment. Cancer Cell 2012; 21: 309-22. [CrossRef]

14. Lu P,Weaver VM, Werb Z. The extracellular matrix: A dynamic niche in cancer progression. J Cell Biol 2012; 196: 395-406. [CrossRef]

15. Landskron G, De la Fuente M, Thuwajit P, Thuwajit C, Hermoso MA. Chronic inflammation and cytokines in the tumor microenvironment. J Immunol Res 2014; 2014: 149-85. [CrossRef]

16. Koontongkaew $\mathrm{S}$. The tumor microenvironment contribution to development, growth, invasion, and metastasis of head and neck squamous cell carcinomas. J Cancer 2013; 4: 66-83. [CrossRef]

17. Curry JM, Sprandio J, Cognetti D, Luginbuhl A, Bar-ad V, Pribitkin $\mathrm{E}$, et al. Tumor microenvironment in head and neck squamous cell carcinoma. Semin Oncol 2014; 41: 217-34. [CrossRef]

18. Senovilla L, Vacchelli E, Galon J, Adjemian S, Eggermont A, Fridman $\mathrm{WH}$, et al. Trial watch: prognostic and predictive value of the immune infiltrate in cancer. Oncoimmunology 2012; 1: 1323-43. [CrossRef]

19. Fridman WH, Pages F, Sautes-Fridman C, Galon J. The immune contexture in human tumors: impact on clinical outcome. Nat Rev Cancer 2012; 12: 298-306. [CrossRef]

20. Hoffmann TK, Dworacki G, Tsukihiro T, Meidenbauer N, Gooding W, Johnson JT, et al. Spontaneous apoptosis of circulating T lymphocytes in patients with head and neck cancer and its clinical importance. Clin Cancer Res 2002; 8: 2553-62.

21. Chikamatsu K, Sakakura K, Whiteside TL, Furuya N. Relationships between regulatory $\mathrm{T}$ cells and CD8+ effector populations in patients with squamous cell carcinoma of the head and neck. Head Neck 2007; 29: 120-7. [CrossRef]

22. Boucek J, Mrkvan T, Chovanec M, Kuchar M, Betka J, Boucek $\mathrm{V}$, et al. Regulatory $\mathrm{T}$ cells and their prognostic value for patients with squamous cell carcinoma of the head and neck. J Cell Mol Med 2010; 14: 426-33. [CrossRef] 
23. Hanakawa H, Orita Y, Sato Y, Takeuchi M, Ohno K, Gion Y, et al. Regulatory T-cell infiltration in tongue squamous cell carcinoma. Acta Otolaryngol 2014; 134: 859-64. [CrossRef]

24. Wallis SP, Stafford ND, Greenman J. Clinical relevance of immune parameters in the tumor microenvironment of head and neck cancers. Head Neck 2015; 37: 449-59. [CrossRef]

25. Watanebe Y, Katou F, Ohtani H, Nakayama T, Yoshie O, Hashimoto K. Tumor-infiltrating lymphocytes, particularly the balance between CD8(+) T cells and CCR4(+) regulatory $\mathrm{T}$ cells, affect the survival of patients with oral squamous cell carcinoma. Oral Surg Oral Med Oral Pathol Oral Radiol Endod 2010; 109: 744-52. [CrossRef]

26. Condeelis J, Pollard JW. Macrophages: obligate partners for tumor cell migration, invasion and metastasis. Cell 2006; 124: 263-6. [CrossRef]

27. Zhang QW, Liu L, Gong CY, Shi HS, Zeng YH, Wang XZ, Zhao YW, et al. Prognostic significance of tumor-associated macrophages in solid tumor: a meta-analysis of the literature. PLoS One 2012; 7: e50946. [CrossRef]

28. Accomando WP, Wiencke JK, Houseman EA, Butler RA, Zheng $\mathrm{S}$, Nelson $\mathrm{HH}$, et al. Decreased NK cells in patients with head and neck cancer determined in archival DNA. Clin Cancer Res 2012; 18: 6147-54. [CrossRef]

29. Xing F, Saidou J, Watabe K. Cancer associated fibroblasts (CAFs) in tumor microenvironment. Front Biosci 2010; 15: 166-79. [CrossRef]

30. Wheeler SE, Shi H, Lin F, Dasari S, Bednash J, Thorne S, et al. Enhancement of head and neck squamous cell carcinoma proliferation, invasion, and metastasis by tumor-associated fibroblasts in preclinical models. Head Neck 2014; 36: 385-92. [CrossRef]

31. Rosenthal EL, McCrory A, Talbert M, Carroll W, Magnuson JS, Peters GE.Expression of proteolytic enzymes in head and neck cancer-associated fibroblasts. Arch Otolaryngol Head Neck Surg 2004; 130: 943-7. [CrossRef]

32. Ostman A, Augsten M. Cancer-associated fibroblasts and tumor growth -bystanders turning into key players. Curr Opin Genet Dev 2009; 19: 67-73. [CrossRef]

33. Desmouliere A, Guyot C, Gabbiani G. The stroma reaction myofibroblast: a key player in the control of tumor cell behavior. Int J Dev Biol 2004; 48: 509-17. [CrossRef]

34. Kawashiri S, Tanaka A, Noguchi N, Hase T, Nakaya H, Ohara T, et al. Significance of stromal desmoplasia and myofibroblast appearance at the invasive front in squamous cell carcinoma of the oral cavity. Head Neck 2009; 31: 1346-53. [CrossRef]

35. Vaupel P. Tumor microenvironmental physiology and its implications for radiation oncology. Semin Radiation Oncol 2004; 14 : 198-206. [CrossRef]

36. Hoogsteen IJ, Marres HA, Bussink J, van der Kogel AJ, Kaanders JH. Tumor microenvironment in head and neck squamous cell carcinomas: Predictive value and clinical relevance of hypoxic markers. A review. Head Neck 2007; 29: 591-604. [CrossRef]

37. Janssen HL, Haustermans KM, Balm AJ, Begg AC. Hypoxia in head and neck cancer: How much, how important? Head Neck 2005; 27: 622-38. [CrossRef]

38. Kim Y, Lin Q, Glazer PM, Yun Z. Hypoxic tumor microenvironment and cancer cell differentiation. Curr Mol Med 2009; 9: 425-34. [CrossRef]
39. Vaupel P, Harrison L. Tumor hypoxia: Causative factors, compensatory mechanisms, and cellular response. Oncologist 2004; 9 (suppl 5): 4-9. [CrossRef]

40. Bussink J, Kaanders JH, van der Kogel AJ. Tumor hypoxia at the micro-regional level: clinical relevance and predictive value of exogenous and endogenous hypoxic cell markers. Radiother Oncol 2003; 67: 3-15. [CrossRef]

41. Vaupel P. Hypoxia and aggressive tumor phenotype: implications for therapy and prognosis. Oncologist 2008; 13 (suppl 3): 21-6. [CrossRef]

42. Price JM, Robinson SP, Koh DM. Imaging hypoxia in tumors with advanced MRI. QJ Nucl Med Mol Imaging 2013; 57: 257-70.

43. Marcu LG, Harriss-Phillips WM, Filip SM. Hypoxia in head and neck cancer in theory and practice: A PET-Based Imaging Approach. Comput Math Methods Med 2014; 2014: 624-42. [CrossRef]

44. Semenza GL. Hypoxia-inducible factors in physiology and medicine. Cell 2012; 148: 399-408. [CrossRef]

45. Weidemann A, Johnson RS. Biology of HIF-1alpha. Cell death and differentiation 2008; 15: 621-7. [CrossRef]

46. Semenza GL. HIF-1, O(2) and the 3 PHDs: how animal cells signal hypoxia to the nucleus. Cell 2001; 107: 1-3. [CrossRef]

47. Beasley NJ, Leek R, Alam M, Turley H, Cox GJ, Gatter K, et al. Hypoxia-inducible factors HIF-1alpha and HIF-2alpha in head and neck cancer: relationship to tumor biology and treatment outcome in surgically resected patients. Cancer Res 2002; 62: 2493-7.

48. O'Brien ER, Garvin MR, Stewart DK, Hinohara T, Simpson JB, Schwartz SM, et al. Osteopontin is synthesized by macrophage, smooth muscle and endothelial cells in primary and restenotic human coronary atherosclerotic plaques. Arterioscler Thromb 1994; 14: 1648-56. [CrossRef]

49. Le QT, Sutphin PD, Raychaudhuri S, Yu SC, Terris DJ, Lin HS, et al. Identification of osteopontin as a prognostic plasma marker for head and neck squamous cell carcinomas. Clin Cancer Res 2003; 9: 59-67.

50. Kaluz S, Kaluzova M, Liao SY, Lerman M, Stanbridge EJ. Transcriptional control of the tumor- and hypoxia-marker carbonic anhydrase 9: Aone transcription factor (HIF-1) show? Biochim Biophys Acta 2009; 1795: 162-72.

51. Beasley NJ, Wykoff CC, Watson PH, Leek R, Turley H, Gatter $\mathrm{K}$, et al. Carbonic anhydrase IX, an endogenous hypoxia marker, expression in head and neck squamous cell carcinoma and its relationship to hypoxia, necrosis and microvessel density. Cancer Res 2001; 61: 5262-7.

52. Nordsmark M, Overgaard M, Overgaard J. Pretreatment oxygenation predicts radiation response in advanced squamous cell carcinoma of the head and neck. Radiother Oncol 1996; 41: 31-9. [CrossRef]

53. Brizel DM, Dodge RK, Clough RW, Dewhirst MW. Oxygenation of head and neck cancer: changes during radiotherapy and impact on treatment outcome. Radiother Oncol 1999; 53: 113-7. [CrossRef]

54. Rudat V, Vanselow B, Wollensack P, Bettscheider C, Osman-Ahmet $\mathrm{S}$, Eble MJ, et al. Repeatability and prognostic impact of the pretreatment $\mathrm{pO}(2)$ histography in patients with advanced head and neck cancer. Radiother Oncol 2000; 57: 31-7. [CrossRef]

55. Overgaard J, Eriksen JG, Nordsmark M, Alsner J, Horsman MR, Danish Head and Neck Cancer Study Group, et al. Plasma osteopontin, hypoxia, and response to the hypoxia sensitizer nimorazole in radiotherapy of head and neck cancer: results from the DAHANCA 5 randomised double-blind placebo-controlled trial. Lancet Oncol 2005; 6: 757-64. [CrossRef] 